\title{
Los límites artísticos en los ensayos sobre arte y estética de Baldomero Sanín Cano ${ }^{1}$
}

\section{Artistic Boundaries in Baldomero Sanín Cano's Essays on Art and Aesthetics}

\author{
Efrén Giraldo \\ Departamento de Humanidades, Universidad Eafit. Medellín, Colombia. \\ egiral25@eafit.edu.co
}

\section{Resumen}

La obra del ensayista y crítico colombiano Baldomero Sanín Cano ha despertado recientemente el interés académico, a causa de su participación en las discusiones estéticas y literarias de Colombia y América Latina. Pese a esto, se carece de trabajos que valoren su aporte a la discusión sobre expresiones plásticas y visuales en Colombia. Este texto se ocupa de uno de los temas recurrentes de su trabajo: las diferencias entre las artes y, más específicamente, entre las artes de la imagen y de la palabra. Se revisa el estado de la discusión en torno a los textos de Sanín Cano que se ocuparon de artes visuales y estética. Por último, se consideran algunos de ellos y se postula una hipótesis sobre el papel que el parangón entre pintura y poesía tiene en sus ideas sobre la taxonomía de las artes.

Palabras clave: Baldomero Sanín Cano, ensayo, crítica, ideas estéticas en Colombia, artes del tiempo y artes del espacio, clasificación de las artes.

\begin{abstract}
Baldomero Sanín Cano's work has been recognized as a significant milestone in literary and artistic Colombian and Latin-American scene. Despite of this, there are few researches on his contribution to the discussion on plastic and visual arts in Colombia. The article discusses one of the recurrent Sanín Cano's topics: the differences between arts and, more precisely, between picture arts and word arts. In order to analyze this problem, the state of art related to Sanín Cano's essays is discussed. The article shows the role of arts classifications in aesthetic theory. Moreover, the article analyzes some Sanín Cano's texts in order to convey the role of the comparison between painting and poetry in his thesis about arts taxonomy.
\end{abstract}

Keywords: Baldomero Sanín Cano, Essay, Critique, Aesthetic ideas in Colombia, Time arts and space arts, Arts classification.

1 Este artículo es el resultado de la investigación Baldomero Sanín Cano. Antología de textos sobre arte y estética, realizada con Fondos de la Dirección de Investigación de la Universidad EAFIT durante la vigencia 2013. La investigación tuvo al autor de este texto como investigador principal y a los estudiantes de la Maestría en Hermenéutica Literaria Adelaida Acosta Posada y Juan Julián Alzate como asistentes. 


\section{Sanín Cano, crítico de arte y lector de estética}

La obra de Baldomero Sanín Cano ha recibido atención de la academia en estudios que analizan, fundamentalmente, su producción como ensayista y crítico literario. Solo en pocas ocasiones, su actividad como comentarista de artes y analista de problemas de la estética y la imagen ha sido atendida con algún cuidado. Estos trabajos, relativamente recientes, se han ocupado sobre todo de los textos que tratan de pintura y, muy especialmente, de los dos artículos sobre la exposición de Andrés de Santamaría ${ }^{2}$ y sus alumnos en Bogotá, publicados en la Revista Contemporánea en 1904 y 1905 con el título "El impresionismo en Bogotá" En este apartado, se reseñan tales estudios y se hace un balance de sus aportes a la consideración de Sanín Cano como un autor que tuvo en cuenta expresiones estéticas diferentes a la literatura, donde ejerció su actividad como un prolífico crítico, y cuya importancia continental aún no ha sido del todo establecida. En los capítulos siguientes, se amplía la perspectiva de análisis que hay en tales precedentes.

La reflexión sobre Sanín y las artes visuales es reciente. En su libro de 1978, Procesos del arte en Colombia, el historiador del arte Âlvaro Medina consideró la participación de Sanín Cano en la polémica de 1904 alrededor de la exposición de Andrés de Santamaría y sus discípulos. Además de recordar que Sanín era sólo un año menor que Santamaría (70) y proponer vínculos generacionales e ideológicos entre ambos, el texto ponderó los aportes del ensayista antioqueño a la consideración de las corrientes renovadoras del arte colombiano, lo presentó en el contexto de la discusión sobre el impresionismo con contemporáneos suyos como Max Grillo y Ricardo Hinestrosa Daza y mostró las apreciaciones del ensayista sobre la nueva pintura. Medina habla del excesivo entusiasmo por la obra de Santamaría en un ensayista tradicionalmente reposado (73-4) y del error que supuso en Sanín caracterizar la emoción en el Impresionismo como un elemento inexistente, extrapictórico (70).

Posteriormente, uno de los autores que dio lugar importante a la preocupación artística de Sanín Cano fue David Jiménez Panesso, quien en su libro Historia de la crítica literaria en Colombia, de 1992, se ocupó más específicamente de los textos dedicados al impresionismo en Bogotá, además de señalar la importancia del autor como uno de los principales críticos y ensayistas en Colombia y particularmente como el representante de la crítica modernista, si tenemos en cuenta sus múltiples artículos sobre Silva, Rubén Darío, Valencia, Brandes, Taine o Nietzsche. La aproximación de Jiménez buscaba respaldar el acercamiento a las ideas de Sanín sobre el modernismo poético hispanoamericano con una tesis sobre la autonomía del arte, la cual el investigador situó en los textos “De lo exótico" (1977), "Una gran aventura:

2 Pintor colombiano (1860-1945) introductor del Impresionismo en su país. Fue director de la Escuela de Bellas Artes. En 1904 protagonizó la más importante polémica del primer arte moderno en Colombia, de la cual participó, con otros críticos y artistas, Baldomero Sanín Cano, quien a su modo lideró la defensa del nuevo arte. 
el arte" (2012) y "El impresionismo en Bogotá" (2006). Como lo indica el título del libro, el propósito no era la producción de crítica de arte de Sanín Cano, sino, más bien, cotejar las visiones que el ensayista tenía de la pintura moderna con sus ideas sobre la poesía, la literatura y la cultura. Jiménez dedica una sección de su libro al arte visual, "El debate sobre el impresionismo", y otra, "Humanismo y porvenir de la cultura”, a aspectos más generales, donde analizó la preocupación de Sanín Cano por el futuro del arte y el humanismo en la sociedad de masas. En el primero de estos capítulos, además de indicar la centralidad que tienen en el primer Sanín los conceptos de autonomía y libertad formal y la impronta que ello deja en su vocación modernizadora, Jiménez se centró en dos ideas: 1) el rechazo de Sanín a la imposibilidad de una representación fiel de la realidad en la pintura impresionista y 2) las bases que la defensa del impresionismo dio a su reflexión sobre la poesía moderna. Según Jiménez, "la polémica sobre el impresionismo es otra versión de la ya trajinada disputa sobre el modernismo" (118).

Si bien uno de los tópicos más interesantes de los dos ensayos sobre el impresionismo considerados por Jiménez es la relación entre arte y literatura, el historiador de la crítica literaria en Colombia no analizó este asunto, ni consideró el parangón pintura-poesía como una de las claves para entender el modernismo de Sanín, quizás porque su propósito fue, más bien, dar un soporte estético a la pregunta por la literatura.

Un trabajo que discute las ideas estéticas en Sanín y, más ampliamente, sus ideas sobre arte y cultura, es el artículo de Daniel Jerónimo Tobón “Arte y cultura: el pensamiento estético de Sanín Cano". Allí, siguiendo la hipótesis de Jiménez sobre el predominio del concepto de autonomía artística en las primeras obras críticas de Sanín, el autor analiza también los textos dedicados al impresionismo y al concepto de cultura. Si bien no hay grandes variaciones en el tratamiento del corpus (limitado a los dos textos mencionados, más la conferencia "Una gran aventura: el arte" ) y el ensayo "De lo exótico", el artículo de Tobón avanza en dos direcciones importantes: 1) asocia la autonomía general del arte ya advertida por Jiménez con las autonomías de cada una de las expresiones estéticas (154) y 2) acerca al ensayista colombiano a las ideas estéticas de Kant, Schopenhauer y Nietzsche (149), lo que da a las opiniones de Sanín Cano sobre libros y cuadros un marco estético poco explorado. Un aporte de este artículo es que soporta sobre tres líneas fundamentales la dimensión moderna de Sanín (Tobón usa el término "modernista"), un aspecto trabajado a veces de manera ligera por otros autores cuando relacionan el papel de Sanín Cano como "modernizador" de la cultura colombiana con sus opiniones específicas sobre arte y literatura. Las líneas señaladas por Tobón son la belleza como "principio supremo del arte", la autonomía y la "defensa, modernista y antirromántica, de la diferenciación e independencia de artes como la novela y la pintura en razón de sus medios" (152).

Este último reconocimiento supone la posibilidad de ver en la pregunta por los límites entre pintura y poesía una de las claves del modernismo de Sanín, aunque Tobón no analiza el origen de este problema ni las manifestaciones que tiene en los 
otros textos del autor. Tobón caracteriza como antirromántica esta búsqueda de independencia de las artes, pese a que hay en ello una respuesta modernista con raíces más remotas (quizás la respuesta de Lessing en su Laocoonte a Batteux). Tobón interpreta la idea de Sanín Cano sobre las diferencias entre el arte pictórico y el arte literario de manera individualizada "la pintura se diferencia de las demás artes, particularmente de la literatura, por las posibilidades intrínsecas de su medio" (153), un hecho que, como se mostrará más adelante, vale para las ideas de Sanín Cano sobre las relaciones entre todas las artes. Pese a esta consideración generalista del problema y a la falta de aproximaciones a los otros textos sobre artes plásticas de Sanín Cano, Tobón observa con agudeza una contradicción en la defensa que hace Sanín de la independencia de las artes. La encuentra en el hecho de que, en los textos sobre el Impresionismo, el ensayista hubiera recurrido a imágenes prestadas de otras artes para hablar de la irreductibilidad de la pintura a algo que no sea ella misma, como cuando habla de "poema de la luz" y de "acorde misterioso de las notas del color" (153) al referirse a la pintura impresionista.

Sofía Arango y Carlos Arturo Fernández, en su libro Fundamentos estéticos de la crítica literaria en Colombia. Finales del siglo XIX y comienzos del siglo XX, se refieren también a Sanín Cano y conectan sus ensayos críticos con las dos esferas, la literaria y la plástica, aunque su objetivo es mostrar cómo se dio la discusión estética como respaldo a preguntas específicas de la literatura y no profundizan realmente en su visión modernista.

En resumen, podría decirse que la aproximación al Sanín Cano crítico de arte y analista de problemas estéticos se ha circunscrito a intereses como respaldar o complementar el análisis de sus textos de crítica literaria con el examen de algunos de sus escritos sobre pintura, discutir sus ideas sobre el arte moderno, observar sus consideraciones sobre el arte en el seno de su interés "general" en la cultura, examinar el papel de sus preguntas sobre la autonomía artística y las relaciones entre las artes para proponer una inscripción literaria y estética del género ensayístico ${ }^{3}$.

En este artículo se busca, sobre la base de un corpus de textos sobre arte, estética e imagen más amplio del considerado por los autores atrás mencionados, vislumbrar el papel que el parangón entre las artes, y más específicamente entre la literatura y la plástica, tiene en la reflexión que Sanín Cano hizo sobre artes como la pintura, el dibujo, la arquitectura o el cine. La siguiente sección sitúa este problema en la teoría estética y, de alguna manera, explica el uso de las comillas en la anterior oración.

3 Esta vía es la que se sigue en el libro La poética del esbozo. Baldomero Sanín Cano, Hernando Téllez, Nicolás Gómez Dávila, de Efrén Giraldo (2014). Allí, se analizan directamente los textos sobre arte y estética de Sanín, pero con el fin de entender la práctica ensayística en el seno de la producción literaria. 


\section{La clasificación de las artes en la teoría estética. El lugar de los medios artísticos como complemento de la teoría de la mímesis y la belleza}

En su libro Historia de seis ideas. Arte, belleza, forma, creatividad, experiencia estética, Władysław Tatarkiewicz revisa la manera en que se ha pensado la clasificación de las artes desde los griegos hasta mediados del siglo XX. En el segundo capítulo de ese trabajo referencial, "El arte: historia de una clasificación", el teórico polaco expone las diferentes estrategias seguidas por filósofos y críticos para construir una definición de arte y, correlativamente, para hacer una clasificación que dependiera de esa definición matriz. En ella, como veremos más adelante, pintura y poesía (literatura) tienen un papel fundamental, al ser emblemáticas de dos formas características de producción humana.

Ya en 1963, en un artículo intitulado "Classification of Arts in Antiquity", un precedente de su libro, Tatarkiewicz había mostrado cómo, desde la antigüedad griega, poesía y arte pertenecieron a dominios distintos, toda vez que la primera obedecía a la inspiración mientras el segundo se sometía a reglas; esto, hasta el momento en que se empezó a reconocer en ambas la existencia de los dos factores (231), y ya la diferencia debió buscarse en otro ámbito. Se dieron entonces numerosos intentos de clasificación desde los sofistas hasta el período helenístico y se acudió, de esta manera, a varios criterios.

Los sofistas hablaron de artes utilitarias y placenteras y Plutarco añadió una categoría más: la que incluye a las artes que buscan la perfección (232). Platón introdujo una importante inflexión al clasificar las artes según su relación con las cosas reales. Según esto, la clasificación podía ser tripartita: artes que hacen uso de la realidad, artes que producen una nueva realidad y artes que imitan la realidad (233). Aristóteles propuso una división parecida: artes que completan la naturaleza y artes que la imitan (Ibíd.). Después, probablemente, fue Galeno quien propuso una nueva tipología, influyente hasta ahora: artes vulgares (que requieren esfuerzo físico) y artes liberales (de cuño intelectual). Séneca, por su parte, propuso las artes que educan y las artes que recrean. Y después, Quintiliano, probablemente reuniendo ideas precedentes, propuso una nueva clasificación tripartita: artes teoréticas, artes prácticas y artes poiéticas o productivas (234).

Dionisio añadió a las artes productivas el calificativo de "terminadas". Así, su clasificación incluía las artes prácticas, apolestéticas (terminadas), teoréticas y peripoiéticas (que sólo usan la naturaleza) (235). Cicerón, por su parte, habló de artes mayores, mediocres y menores (236) y, también, de artes sonoras y mudas (Idíd.). El cierre de la antigüedad vio a Plotino formular dos propuestas de clasificación: una obedeciendo a los instrumentos usados por cada arte (las que usan las fuerzas de la naturaleza, las que usan sus propios instrumentos y las que usan sólo instrumentos mentales (237) y otra, más enumerativa, pues divide a las artes en aquellas que produ- 
cen objetos físicos, que ayudan a la naturaleza, que imitan la naturaleza, que mejoran y adornan la vida humana y que son puramente intelectuales (237).

Como recuerda el historiador de las ideas polaco, a la concepción antigua de las artes subyace una profunda dualidad. Los griegos notaron qué separaba a las artes expresivas de las artes contemplativas, pero no supieron qué las unía (239). Y no lo hicieron simplemente porque asociaban las primeras con la poesía y las segundas con lo que hoy entendemos por artes plásticas o visuales en sí. Por su parte, tres razones condujeron a los modernos a la idea de "bellas artes": la aspiración a la belleza, la expresión de sentimientos y la tutela de la imaginación (Ibíd.). Para los griegos, las artes fueron algo más cercano a la techné, mientras que la poesía era algo más próximo a la sophia (240). De hecho, en la antigüedad, sólo Filóstrato el Viejo pudo señalar que, para hacer esculturas y pinturas, era necesario tener algo más que habilidad manual (Ibíd.). Como se ve, la dimensión intelectual del arte era algo aún inalcanzable para las reflexiones del momento.

Los aportes del Renacimiento y la Ilustración a la definición y clasificación de las artes se resumen en dos planteamientos: el siglo XVI separó definitivamente las artes de la artesanía, aunque no de la ciencia, mientras que el siglo XVIII unificó las artes en un grupo al que pasaron a pertenecer la poesía, la pintura, la arquitectura, la escultura, la danza y la música (Ibíd.). Si bien el Renacimiento mantuvo, en esencia, el espíritu de las clasificaciones griegas y romanas (en la Edad Media no se producen nuevas teorías significativas sobre la clasificación de las artes), Tatarkiewicz destaca algunas curiosidades, como por ejemplo la que hay en el Lexicon Philosophicum de Rudolph Goclenius (1607). Allí, las artes pueden ser principales o subordinadas, inventivas o instrumentales, puras o manuales (Historia de seis ideas 87). En 1630, cuenta Tatarkiewicz, Johann Heinrich Alsted propuso, en su Encyclopedia, dieciséis divisiones para las artes. Algunas son hilarantes: artes fáciles o difíciles, artes aditivas y que sustraen, artes necesarias ("como el pastoreo") e innecesarias ("como la interpretación"), artes honestas ("como la pintura") y deshonestas ("como el proxenetismo") (88).

Pese a esta abundancia de clasificaciones en el Renacimiento y el Barroco, Tatarkiewicz señala la imposibilidad que se tuvo en ese momento para encontrar criterios unificadores, y por ende categorías conducentes a una clasificación. Indica que se debió esperar hasta finales del siglo XVII, cuando Francis Bacon planteó la clasificación de las disciplinas, para que apareciera un concepto poderoso que ayudara a la síntesis definitiva del concepto de arte: la imaginación. Las artes, según el filósofo y ensayista inglés, se diferencian de las ciencias en que no se basan en la razón, y, de la historia en que no se apoyan en la memoria (89). Sin embargo, para Bacon, la imaginación solo se vinculaba con la poesía, mientras que las demás artes, la pintura y la música, eran sólo "destrezas técnicas" que deleitaban y mejoraban al ser humano, como la medicina o la cosmética (Ibíd.).

Ahora bien, el término boas artes, usado por primera vez por Francesco de Holanda en el siglo XVI y luego por Charles Perrault en 1690 (beaux arts), dio a Charles 
Batteux el sustento para su famosa clasificación de las bellas artes, consignada en un libro con el elocuente título Les Beaux arts réduits à un même principe, publicado en 1747. En esta clasificación, la belleza tuvo un papel central, hecho que ayudó a acercar entre sí expresiones tan diferentes como el arte visual y el arte verbal. Esta propuesta se difundió rápidamente por Europa (91) y tuvo escasas variaciones. Como recuerda Tatarkiewicz, este criterio estético permitió refinar la definición de arte y aplicarla a productos y actividades muy específicos (92).

Ahora bien, si esta clasificación fue aceptada rápidamente y el concepto de bellas artes se convirtió en habitual en las disquisiciones de eruditos y conocedores, no pasó así con las posibles subcategorías que permitieran clasificar eventualmente esas bellas artes. Tal como sostiene Tatarkiewicz, la posible inclusión de las bellas letras dentro de las bellas artes y la evidente lejanía entre el arte visual y el arte verbal impidió una posible subdivisión. El polaco lo expone contundentemente: "La Ilustración observó la profunda dualidad que existe en la creatividad; la producción de palabras y la producción de cosas" (93).

En el Laocoonte de Gothhold Ephraim Lessing, de 1796, Tatarkiewickz ve la consumación de las reservas hacia la inclusión de artes poéticas y artes del disegno en una misma categoría (Ibíd.). Aunque cabría ver, en este libro, una reacción a unificar las artes y a la posibilidad de unirlas en una especie de síntesis, siguiendo el interés que todas ellas tienen en la mímesis y en la belleza. En este punto, Kant hizo también un aporte decisivo, como lo había hecho en otros dominios de la acción y la producción humanas. Según Tatarkiewicz, su principal aporte fue haber diferenciado "tantos tipos de artes como modos de expresión y transmisión de ideas y sentimientos hay en el hombre" (95). Valor especial tiene también el hecho de que Kant hubiera dividido las bellas artes según correspondieran a uno de tres modos: palabras, sonidos y gestos. Lo que vemos, con las ideas de Kant y Lessing, es, en resumen, la aparición de un nuevo concepto, aún vigente: el de medio artístico. Mismo que, como señalará posteriormente Simon Marchán Fiz, se convertiría en el concepto de "lenguaje artístico", de amplio recibo en la modernidad de la que Sanín Cano es heredero (La estética en la cultura moderna 225-248).

A continuación, el siglo XIX produjo nuevos ordenamientos, atendiendo a diferentes criterios, en los que el concepto de medio introducido por Lessing tuvo gran acogida. De hecho, acercar (o alejar) actividades centradas en las palabras o en las imágenes (obras hechas con signos convencionales u obras hechas con signos naturales, como se decía antiguamente) ha sido uno de los motivos centrales que animó la discusión sobre la autonomía de las artes, sus vecindades y sus interferencias. La diferencia fundamental entre la pintura y la poesía, como indicó Lessing en su célebre fórmula, es que la primera muestra cuerpos que interactúan en el espacio, mientras que la segunda presenta acciones que se despliegan en el tiempo.

Aunque a finales del siglo XIX y principios del XX (momento en el que Sanín produjo sus textos de tema estético y artístico más importantes) se descubren intentos 
de interrelación entre las disciplinas artísticas (particularmente a través de expresiones mixtas como el drama musical y el cine), las críticas a este impulso también fueron muy activas. De hecho, en buena medida, este intento de definición de lo específico en cada arte (y su consecuencia programática, es decir, cómo hacer que cada arte se desarrolle sin influencia de otras expresiones y busque sus fundamentos últimos) dio una de las caras más distintivas a la concepción de lo moderno en el arte.

Ahora bien, este núcleo de pensamiento, que buscaba la especificidad de cada arte, y cuya aparición habría que remontar a la defensa que críticos y escritores hicieron del Impresionismo en Francia a partir de la década de 1860 (Solana, El Impresionismo: la visión original), se fue decantando hasta generar intentos de lectura de la producción reciente como un intento de independizar la práctica de las artes y, más específicamente, liberar a las artes plásticas de su obligación narrativa. Estos textos, en los que los escritores defendieron a los impresionistas, precisamente por haberse emancipado de lo literario, sentaron las bases que después vamos a ver en la crítica y en la teoría del arte que acompañó la defensa de prácticas como el arte abstracto.

Como es sabido, este cuerpo de ideas cristalizó con gran contundencia en la obra del crítico norteamericano Clement Greenberg (1909-1994), quien en la década del treinta signó lo moderno en la pintura por un intento de autodefinición en el que esta debía escapar a otras influencias que no fueran las de su propio medio. Sin duda alguna, no exageró Arthur Danto cuando le atribuyó a Greenberg uno de los tres paradigmas de la definición del arte a lo largo de la historia (Después del fin del arte 79-98).

Dos textos escritos por Greenberg en la década de 1930 ilustran bien este interés, ya manifestado en Colombia en 1904 y 1905 por los textos de Sanín Cano sobre el impresionismo. No hacemos esta alusión comparativa para indicar, ni mucho menos, que el ensayista colombiano logró anticipar ideas de otro contexto. Sin embargo, como aspira a mostrar el examen de los textos sobre arte del ensayista antioqueño, sí es del interés de este trabajo indicar cómo su postura ante los límites y vecindades entre las artes es una de las facetas más desatendidas de su modernismo, pese a que esta apuesta autonomista es uno de los aspectos más característicos en el campo de la crítica de arte.

En "Vanguardia y kitsch", un texto de 1938, Greenberg expuso que el rasgo distintivo de las artes modernas es delimitar su área de competencia y sacar inspiración de su propio medio (15). En este sentido, el carácter plano, el uso de formas y colores y el formato cuadrangular serían los aspectos que definirían la práctica de la pintura. La intromisión de cualquier elemento que simulara lo tridimensional o que pusiera énfasis en algún aspecto narrativo o literario violaría la vocación que la pintura tendría por explorar su propia área de competencia (Ibíd.). En este proceso, que según Greenberg se fue acentuando en el siglo XX, se puede descubrir como origen de la insurrección pictórica contra la influencia perniciosa de las otras artes el Impresionismo, movimiento que habría empezado rechazando los grandes temas, hecho que definió su independencia de la literatura (Ibíd.). Por su parte, en un texto un poco posterior, "Hacia un nuevo Laocoonte", de 1940, Greenberg hermanó el deseo moderno 
de mantener aisladas las esferas de competencia de cada arte, lo que llamó su "pureza", con la crítica que Lessing hizo en el siglo XVIII al intento de unificar todas las artes alrededor de la mimesis y la belleza. En ambos textos, es crucial el hecho de que la pintura debe mantenerse fiel a las restricciones y posibilidades que le da su medio, lo que, de acuerdo con Greenberg, definiría su modernismo. Una actitud que en otro trabajo, "La pintura modernista", publicado en 1960, le permitió asociar la actitud autocrítica de Manet en la pintura con la actitud autocrítica de Kant en la filosofía.

\section{El lugar de la taxonomía artística en la obra crítica de Sanín Cano. Grados, escalas y fronteras}

Conviene aclarar que, aunque Sanín Cano se ocupó del problema de la clasificación de las artes y escribió sobre las relaciones que tienen las disciplinas artísticas, su aproximación al problema estético no se dio desde la teoría. Más bien, recurría a conceptos, nociones y argumentos cuando lo demandaba la necesidad expositiva de cada fenómeno artístico. Sanín fue, sobre todo, un ensayista y un crítico que se aproximó a obras y acontecimientos artísticos sin un aparato teórico, aunque, como se muestra en este trabajo, sí subyacen a sus escritos inquietudes que han preocupado largamente a la teoría estética.

Este es el caso de la clasificación de las artes, sus diferencias y semejanzas, sus maneras de construirse y ser recibidas por el público. Una inquietud que se manifiesta durante toda su carrera y que, pese a ello, nunca encontró un desarrollo sistemático. Este interés parte del parangón entre artes de la imagen y artes de la palabra, tópico que, como ya se dijo, es uno de los motores en la definición y clasificación de las artes en la historia occidental. Para empezar, digamos que en gran parte de los textos de Sanín hallamos alusiones a la literatura en clave pictórica o referencias comparativas entre las artes ${ }^{4}$. Para el caso específico de los textos dedicados estrictamente a los problemas de la estética, la imagen y las artes plásticas, debemos señalar que el interés por las relaciones interartísticas es permanente y tiene una presencia constante en su trabajo.

Sus primeras inquietudes sobre el tema de los límites entre las artes aparecen en escritos donde usa una forma de arte para explicar otra. En estos casos, se trata sobre todo de un recurso argumentativo.

Para empezar la revisión de este punto, convendría examinar la visión general del arte de Sanín Cano, la cual encontramos en aquellos textos donde se pregunta por el porvenir de la obra de arte y las humanidades en una sociedad que, como la de su tiempo, y según él, ya no daba a estos dos elementos en lugar preferencial. En

4 En un texto, "La tiranía del medio ambiente", hablando de la literatura como un impulso, leemos: "Tanto placer así tendría el molusco que traza líneas sobre la roca, si supiera que ellas iban a ser materia de emociones artísticas para seres inteligentes" (297). 
su texto-conferencia "Una gran aventura: el arte"), trabajo en el que podemos ver un resumen de sus ideas sobre el papel de lo estético en la civilización, Sanín indicó que el arte abarcaba todas las manifestaciones que tuviesen una pretensión estética. El arte es una expresión humana en la que las otras (filosofía, religión, ciencia) se apoyan y de ello se deriva su centralidad y relevancia antropológica. Sugiere que la dimensión que reúne a las artes y las asimila es la representacional, y añade que como rasgos unificadores pueden contarse también sus valores histórico, cultural y humano. Por otro lado, el valor artístico o espiritual es uno de los dos conceptos que apoyan su idea de civilización: el otro es el progreso material, que prodiga desarrollos y utilidades prácticas. Uno es propiamente la civilización, el otro la cultura. Ahora bien, lo que diferencia a ambas esferas es que en una reina la razón y en la otra, la imaginación. Al ser esta última la facultad característica del arte, Sanín Cano se acercó al criterio que, desde el Renacimiento, está en el corazón de la pregunta por la facultad humana que genera la actividad artística. El territorio de la imaginación, al estar en las antípodas de la razón, no admite una comprensión instrumental y progresiva de las habilidades artísticas. Para Sanín, los animales son capaces de ciencia y tecnología, pero no de arte, aunque haya simetría en lo que construyen.

Con esta concepción de entrada, donde la imaginación y la representación son medulares, podemos ver la manera en que el autor se ocupa de las relaciones interartísticas para explicar la naturaleza o las condiciones específicas de alguna forma de arte. En el texto "El arte y la línea recta"), por ejemplo, se sirve de un elemento de orden plástico para referirse a cosas decorativas e, incluso, relacionadas con el cuerpo humano. Luego de emparentar las artes alrededor de propiedades como la gracia, la armonía, la expresividad y la belleza, que resultan complementarias de una concepción artística centrada en la representación producida por la imaginación, expone con preocupación cómo las nuevas corrientes estéticas, concretamente el funcionalismo y el minimalismo, instalan el imperio de la línea recta, a la que ve como elemento extraño a la naturaleza. La motivación para el texto, hay que recordarlo, está fuera del arte y procede del universo de la moda femenina, ámbito donde el ensayista advierte con preocupación la aparición de un interés por lo ortogonal.

En otro texto, "La civilización manual", aunque no se ocupa sólo del arte, Sanín hace una defensa de la tradición mecánica, frente al predominio excesivo de la liberal o espiritual. En este debate, Sanín refleja el escollo de los intentos de clasificación de las artes en Occidente: el esfuerzo material como característica del arte. Al hacer la apología de la actividad física, Sanín Cano hace algo parecido a los historiadores del arte que, en aquellos años, emprendieron el elogio de la mano. Algo que, sin duda, buscaba dar al arte y a las tareas estéticas una dimensión intelectual y moral más amplia de la que permitía una concepción servil y utilitaria 5 .

5 Es el caso del historiador del arte francés Henri Focillon y, precisamente, su Éloge de la main, de 1934, donde el proceso de la historia del arte y las ideas estéticas se muestran como una herencia manual (1981). 
En el texto de Sanín resulta interesante, por otro lado, la manera en que las actividades de la mano se vinculan con la formación de las habilidades perceptivas, sobre todo las visuales, imprescindibles en la plástica. No obstante, pese a esta cooperación perceptiva, se insinúan allí las limitaciones que tienen las palabras cuando el ser humano quiere expresarse; uno de los argumentos más usados por Sanín cuando formula una comparación entre la literatura y otra expresión artística:

La mano tiene una inagotable variedad de gestos y actitudes que, cultivados con amor y rigurosamente clasificados, llegarían a servir para representar matices de sentimiento que la lengua articulada logra analizar con vagos circunloquios, sin haber formulado todavía la palabra precisa con que puedan representarse. "Amor" es palabra que sirve para expresar sentimientos tan diversos como el afecto que une a los sexos, o el cariño de la madre a sus hijos o la afición del bibliófilo a sus libros. Una mano suave expresa en una leve extensión o contracción de los músculos un poema de pasión contenida, profunda, ante la cual es frustránea en sus esfuerzos la elocuencia de las meras palabras. Las sensaciones de gusto y de olfato son parcialmente, acaso en su totalidad, meras formas del sentido del tacto (39).

Se ve también en este pasaje una idea que aparece insistentemente en otros textos: la índole convencional, y si se quiere contractual, del lenguaje. Un tópico que parece invocarse para señalar, si no la superioridad de la imagen, sí por lo menos su equiparación cualitativa con el lenguaje. No en vano, Sanín menciona la influencia de la mano en la escritura y sugiere que, acaso, lo visual es una dimensión fundacional de lo literario.

El artículo "Del origen del arte", por su parte, concluye con unas líneas en donde la respuesta de la naturaleza se muestra como el agente que engendra lo estético, tanto en artes plásticas como en literatura:

nueva visión creadora, presente no sólo en las obras de arte, en el paisaje de Corot, en los árboles y llanuras espirituales de Turner, en las melancólicas y transparentes sinfonías de color de Segantini, y en el estrépito luminoso de las praderas florecidas de Lieberman, sino también en la prosa estremecida de los novelistas modernos y en la poesía multánime, vibrante, luminosa y sugestiva de los últimos tiempos (139).

Otros textos exponen nuevas formas de relación. “Tenaz como la fealdad”, ensayo dedicado a la influencia perniciosa del art nouveau en la decoración, plantea que pintura y escultura se libraron por su superioridad dentro de la creación plástica y que, al contrario de lo que se pudiera suponer, el impacto de la ola de volutas y ornamentaciones intrincadas ocurrió con indiferencia de los progresos evidentes que hicieron las artes siempre de manera separada. Ahora bien, la explicación de por qué en fecha tan tardía como 1925 existen aún los adefesios decorativos del art nouveau en 
Bogotá, se apoya en un argumento donde aparece de nuevo la relación ente las artes. Las decoraciones de la casa que motiva la redacción del texto fueron emprendidas a partir de unos cartones y catálogos ilustrados que la dueña trajo de Europa. Fue la imagen bidimensional la que habría guiado entonces, en lo tridimensional, es decir, en su aplicación práctica, la realización de un estilo. Nuevamente, como en otros textos, el cierre del ensayo intenta mostrar que los problemas de las artes visuales, en este caso la arquitectura, aparecen también en la literatura:

Hubo su art nouveau en poesía, en las amplias ondulaciones y en los períodos simétricos de laboratorio y aun en la manera de exponer las teorías y descubrimientos científicos. Para que la comparación ocupe todavía un plano más extenso basta observar cómo surgen de repente en las varias formas de literatura y hasta en las actividades más modestas del periodismo, curiosas producciones que parecen, en su llaneza complicada de graciosos arabescos, casos atávicos de aquella familia artística denominada por los bisabuelos de las generaciones últimas arte nuevo de representar la vida en todos sus aspectos (79).

No debemos olvidar, en este contexto de la literatura y el lenguaje como elementos que sirven para aquilatar las excelencias o singularidades de lo visual y lo pictórico, la operación argumentativa inversa: estetizar la actividad del escritor otorgándole calificativos provenientes del universo visual. Por ejemplo, en "Un enigma sentimental resuelto (John Ruskin)", Sanín expone la actividad escrita del crítico inglés como un ejemplo de arte: "Era verdaderamente un mago de la paleta verbal. Parecía como si el estudio de los grandes pintores y su conocimiento práctico, de los secretos de ese arte de prodigio lo hubieran habilitado para infundirle a la palabra el sortilegio del pincel" (510). También, al hablar de la impresión de tormento que da la obra del crítico, expone: "Es algo como el dejo extrahumano que queda en el paladar del espíritu después de contemplar aquellas telas de artistas españoles que se complacían en la evocación del dolor y de los aspectos de la muerte de Cristo y de sus adoradores" (511).

La inquietud de Sanín por los límites entre las expresiones estéticas aparece también en textos que tratan sobre alguna de las artes, diferentes a la literatura y la pintura. Allí es evidente su interés por plantear vecindades y distancias, e incluso interferencias, a las cuales ve casi siempre como dañinas. Un buen ejemplo de este proceso argumentativo lo vemos en un texto llamado "El Arte de Berta Singermann", trabajo sobre una declamadora, cantante y actriz argentina que lo impresionó profundamente cuando vivió en Buenos Aires. Confiesa que lo realizado por la artista, a falta de mejor vocablo, debe recibir el calificativo de "arte". La compara con Leonardo, para decir que es imposible describirlos a ambos y enfatizar la imposibilidad de nombrar artistas que se salen de los cánones, una comparación que no es gratuita si pensamos en el papel que el pintor florentino tuvo en la emancipación del arte de su confinamiento práctico y aplicado. Al hablar de los muchos medios que Sigerman usa, vuelve al tópico según el cual las palabras son limitadas y no alcanzan a expresar 
lo que sí pueden el gesto y la mirada. La palabra, entonces, en este caso, se ve potenciada por el acompañamiento de la mímica y la música. Sanín critica al fonógrafo, al cine y a todos los medios de reproductibilidad, pues cambian la manera en que se comprende la obra de arte. Coincide Sanín Cano en la idea de Benjamin, quien había encontrado en la reproductibilidad el signo técnico de los tiempos. Sin embargo, a diferencia del alemán, la postura de Sanín es alejandrina: al hablar de los logros de la artista, expone que:

es, en suma, un regalo, una compensación providencial a una época durante la cual desaparecen formas de arte como el drama para ser reemplazadas por el cine hablado, por las transcripciones dolorosas de la voz humana en el fonógrafo y en los aparatos de radio, curiosos mecanismos de tortura dispuestos ingeniosamente para distribuir insomnios a domicilio (81).

La contundencia y energía del gesto hacen que la obra vaya más allá de lo teatral. La musicalidad, por ejemplo, tan importante en el arte de Singerman, destruye, para Sanín Cano, la autonomía dramática:

Un drama ha de tener forzosamente una acción y componerse de episodios. Ante el prodigio de la voz humana en los labios de quien ha creado una manera nueva de fascinar la mente de los demás no hay episodio dramático que no se desvanezca y diluya como un vago ensueño. Debe tener además el drama personajes secundarios cuya intervención suele contribuir a la culminación de las escenas más emocionantes. No se concibe la existencia del personaje secundario en un drama donde llenase la escena la personalidad de Berta Singerman (81-2).

Es tan singular lo hecho por Singerman, que la considera una artista ocupada de hacer cosas que van más allá del arte. Una ironía, a propósito de lo anterior, es que, después de que Sanín Cano escribió su texto, Singerman se hubiera dedicado a actuar en el cine.

Ahora bien, la pregunta por la independencia de los medios reaparece, de manera incluso más marcada, en los artículos y ensayos que Sanín Cano dedicó precisamente al cine, uno de los filones más ricos para entender su legado como crítico modernista e, incluso, para evaluar su posición pionera frente a lo que él avizoraba como una inaceptable intromisión de la industria en los dominios del espíritu. Aunque su actitud osciló entre la condena y la valoración, nunca consideró al cinematógrafo como arte $y$, más bien, lo catalogó como un producto del entretenimiento, en el cual cristalizaba el proceso más dañino de las artes contemporáneas en la era del industrialismo y el consumo: su uso de recursos de distintas disciplinas para provocar emociones vívidas en el espectador.

Y es precisamente en sus textos sobre cine donde más se ocupa de la clasificación de las artes, mostrando nuevamente dos caras: por un lado, mira el cine como un arte que supone una obligación de redefinir el teatro y, por el otro, señala que el cine atenta contra la manera tradicional de considerar el arte y su autonomía. 
En "Shakespeare amenazado", uno de sus primeros textos sobre el tema, compara al gran dramaturgo con Chaplin. Atribuye al cine la capacidad de representar el movimiento, no la reflexión, la cual considera más propiamente inducida por el teatro y la literatura. Esta impureza hace que el cine sea la expresión más emblemática del "hombre promedial" (153). "Remover ideas no es ocupación propicia para el conductor de multitudes en los tiempos que corren. Importa andar de prisa lo mismo en la vida que en el teatro y se ha descubierto que las ideas son gravosa impedimenta" (153-4). Expone que el interés en llenar de movimiento el teatro hace que se incluyan piezas bailables en la escena, lo cual mostraría la proclividad a introducir elementos extraños al arte dramático. Todo esto produce un resultado reprochable: el enrarecimiento de las artes escénicas, que intentan replicar lo que hay de ecléctico en el cine.

"El vitáfono", artículo dedicado a una especie de versión primitiva del cinematógrafo, lo hace reflexionar sobre el cine como una expresión mixta, en la que se podrían distinguir con más facilidad el origen múltiple de los elementos constitutivos. Al emitir el vitáfono imágenes mudas en simultaneidad con un sonido ambiental proveniente de otra fuente, Sanín ve el cinematógrafo como un arte realizado por adición de elementos, en el que es difícil ver algún medio constitutivo. El resultado no resulta halagüeño para Sanín, quien no sólo ve que el desarrollo técnico de la innovación aún es limitado, porque el sonido hay que anexarlo a la proyección, sino que también observa en el espectáculo cinematográfico un atentado contra lo que hay de esperanzador como un posible arte apegado a un medio, el de la mímica. Por eso, la posibilidad de un cine sonoro, que el vitáfono auguraba, es para él un retroceso a la mezcla indeseable de medios: "Tratando de combinar el gesto del artista de la pantalla con la declamación retórica, los empresarios del vitáfono van a complicar extraordinariamente el arte cinematográfico sin aumentar sus posibilidades" (171).

La conclusión expone con claridad el trasfondo estético de esta reflexión:

Es verdad ya generalmente admitida que las estrellas del cinematógrafo no son artistas felices trasladadas al tablado ordinario. En rigor, se trata de dos formas de representación tan distintas como la pintura y la poesía y hay una obcecación sin duda en querer combinarlas por medios mecánicos. Hay poetas cuyo empeño se cifra en representar menudamente la realidad en vez de verter las emociones que ella les sugiere, y hay pintores a quienes el influjo de la literatura los desvía de la senda propia y los lleva a cultivar el episodio o la anécdota con detrimento del arte que cultivan. Los cuadros episódicos valen por la habilidad con que el pintor hizo uso de los colores, las líneas, la sombra y la luz, mas no por el cuento que refieren. Asimismo, las páginas descriptivas no encantan porque den idea más o menos justa de un paisaje sino por el encanto de la frase y por las emociones que el artista logre comunicarnos. El arte de la pantalla existe ya de por sí; tiene sus normas rígidas y una de éstas es el silencio. Si el vitáfono llega a convertirse en una realidad, será porque ha logrado crear otro arte muy distinto (Ibíd.). 
En "Diálogo indiferente", uno de sus textos-ensayo, dos personajes conversan sobre la posibilidad de que uno de ellos dedique sus esfuerzos literarios a escribir para la pantalla grande. Señala uno de los personajes que en todas las formas del arte hay una deformación de la realidad. Prueba de ello, según él, es la fotografía, a la que describe de esta manera:

La misma fotografía deforma el espectáculo según la luz, la perspectiva, la disposición relativa de los objetos. Dos fotografías de una misma persona en dos posiciones distintas y tomadas con diferencia de segundos pueden dar imágenes tan diversas que sea casi imposible reconocer en ellas la misma persona. Aun el artista fotográfico pone parte de su alma, de su habilidad en esas obras en que sus principales colaboradores son el sol o la luz eléctrica y a la postre la química y los pinceles (108).

Señala, a continuación, la necesidad de que la ocupación literaria y la cinematográfica se mantengan en sus linderos: "Teniendo presente lo que los adictos al espectáculo de la pantalla reciben con placidez y en ocasiones aplauden no sería difícil escribir para el cine; pero los artistas de la palabra tendrían semejante ejercicio por una usurpación" (Ibíd.).

En estos textos sobre cine, aparece la pregunta por la clasificación de las artes en su expresión más analítica: ¿Es el cine arte? ¿Porta cualidades estéticas? ¿Tiene algo de semejante a lo que ofrecen las demás artes? En cuanto a su capacidad de circulación y penetración en las masas, no duda de que tiene más posibilidades que las artes refinadas, y reconoce, también por contraste, que este tiene muchas más posibilidades que la prensa escrita y la radio. Sin embargo, estas posibilidades, que se apresura a situar en lo educativo e informativo, no permiten que el cine pueda ser considerado como arte.

En el ensayo de 1939 "Un arte educativo", reconoce, no obstante, la integración de los estímulos sensoriales como una de las posibilidades de este nuevo lenguaje:

En la cinta cinematográfica aparece la idea en los labios, en los ojos, en las manos de quien la representa o la difunde. En el cine la emoción viene acompañada de las palabras con que se expresa; los que usan del radio hablan como detrás de una mampara: les falta el calor del gesto para comunicarse con sus oyentes. El radio disminuye el poder de la palabra hablada; el cine multiplica sus efectos y en ocasiones le añade posibilidades de que no hay ejemplo en la cruda realidad (242).

Por último, vale la pena mencionar los textos que Sanín Cano dedicó a la pervivencia de los valores humanísticos en una era caracterizada por la masificación y la incorporación de procedimientos industriales en la producción de entretenimiento y lujo. En este propósito, lo visual cumple un papel esencial, pues en muchos de los intereses que empieza a despertar la imagen en la cultura de masas el ensayista ve una crisis 
del lenguaje. A este respecto, valdría le pena remitirse a un texto donde condena la aparición de las tiras cómicas en los periódicos y el uso que de ellas hacen los lectores.

"Ver y no imitar" es un artículo dedicado a las secciones de periódicos intituladas "historias gráficas", formas mixtas donde se usaban las palabras y las imágenes, bastante populares a mediados de siglo, y que hoy en día conocemos como "tiras cómicas" o "tebeos". El ejemplo que usa Sanín Cano es la obra del autor de cartoons George MacManus, creador de Bringing up father (Educando a papá en su traducción argentina), una tira cómica de amplia circulación en Colombia y América Latina.

Sanín critica el impacto de estas producciones en el público y la importancia que se les da en los periódicos. Son frívolas, fáciles de digerir. Resalta su fealdad y subraya su diferencia con el dibujo artístico. Compara la fealdad que hay en ellas con la fealdad en la literatura (Víctor Hugo), la cual Sanín valida, ya que "en la vida de esos personajes la belleza estaba en el fondo espiritual de sus propósitos y de sus acciones. En tanto que en vano se busca un movimiento realmente generoso en la vida de estos héroes de lo anharmónico, de lo mal intencionado o de lo inexcusablemente estúpido" (408). Traza también una diferencia con la caricatura, a la que ve como una especie de subgénero del retrato. La caricatura "no tiende a hacer odiosas las formas de los personajes por él representados. Su sistema es mostrar por medio de la composición y de la nota explicativa, lo absurdo de una situación, la ineptitud de un sujeto o el dolor de un alma despistada" (408).

\section{El parangón entre pintura y poesía como topos: una reelabora- ción colombiana. Sanín, crítico "modernista" de pintura}

Como se ha señalado, la relación entre pintura y poesía es uno de los tópicos que más aparecen en la teoría estética, en la crítica, en la tratadística y en la escritura sobre arte. Hay allí una de las bases más recurridas a la hora de preguntarse por lo que separa a las expresiones artísticas. Esto ocurre, acaso, porque este parangón testimonia una de las inquietudes más tempranas de la teoría estética, a saber, qué diferencia hay entre construir con cosas y construir con palabras, qué ocurre cuando se hacen obras de arte con convenciones fuertemente fijadas y qué ocurre cuando se hacen con signos naturales, es decir, donde la dimensión representacional (icónica) es más evidente.

Si bien los textos en que Sanín Cano se refiere más explícitamente, y con mayor propiedad, a los límites entre el arte pictórico y el arte literario son sus dos ensayos sobre el Impresionismo, podemos observar en otros textos dedicados a las artes y a la estética una preocupación por los medios de cada una de las diferentes expresiones y, concretamente, por los límites entre las artes hechas con palabras y las artes hechas con imágenes o "cosas". Incluso, sin ser arriesgados, podríamos señalar que al establecer clasificaciones, señalar diferencias y semejanzas o proponer escalas valorativas, el autor usa siempre como referente el contraste entre obras literarias y obras 
plásticas, aun cuando quiere hablar del cine y del teatro, del circo y de la decoración, de la ilustración, de las tiras cómicas y de la arquitectura.

En sus textos sobre pintura, es recurrente la tendencia a juzgar negativamente la intromisión del elemento verbal en el dominio pictórico, algo que, tal como ha señalado la crítica, se da sobre todo en sus textos "El impresionismo en Bogotá I” y "El impresionismo en Bogotá II", los cuales deben verse como dos aproximaciones iniciales, aunque bastante maduras, a la pregunta por lo irreductible que podría haber en la pintura moderna.

En el primero de ellos, plantea la relatividad de las palabras (sobre todo las valorativas) cuando se habla de pintura. Es de resaltar que la relatividad en la representación pictórica, lo que pondría de presente el subjetivismo retiniano del Impresionismo, sea invocada por Sanín también en el lenguaje.

Llamamos rojo, llamamos gris una combinación de colores que no podríamos detallar con una sola palabra. Pero el hecho de usar un solo vocablo para determinar la impresión de color procedente de la naturaleza nos ha llevado de la mano a creer que la impresión es simple. La perfidia del vocablo y la necesidad de simplificar para entendernos de prisa nos hace incurrir en error a cada instante (130).

De cierta manera, al abordar el parangón, Sanín penetra hasta la indagación de la naturaleza de los signos que hay en cada uno de los medios de expresión. Un pasaje del texto resulta clave en este escenario:

Cuando los impresionistas vinieron a representar las cosas como ellos las veían, ya era tiempo de que la pintura se atreviese a ser lo que no había sido sino pocas veces y eso a manera de ensayo. Era tiempo de que la pintura fuese sencillamente la pintura. ¿Había sido tantas cosas? La habían usado para enseñarnos. La habían sometido a torturas extrañas para que representase sistemas filosóficos o enmarañadas concepciones teológicas. Sirvió para transmitir al futuro las hazañas de los héroes (Ibíd.).

Es como si se quisiera mostrar la falta de concordancia entre los dos sistemas, el de los signos convencionales (símbolos) y el de los signos naturales (iconos), para señalar la manera en que el pintor sale avante de la tutela que lo literario ejercía hasta ese momento sobre él.

Se compara la importancia que la naturaleza tiene en los impresionistas con la que tiene en la obra de los escritores y filósofos y nuevamente sobresale el creador visual. Señala, por ejemplo, al hablar de Monet, que el tema es un pretexto para "cantar las sinfonías de color que bullían en su alma” (132). Además de minimizar el tema y por ende su explicación discursiva, Sanín se sirve a la sinestesia, para apoyar en un arte no mimético (la música) su defensa de la pintura como algo irreductible a algo que no sea ella misma. 
En el segundo de sus textos dedicados al Impresionismo, el de 1905, Sanín Cano radicaliza las distancias entre la imagen y la palabra crítica. El tema de esta segunda entrega es, ya no la independencia de la pintura, sino, más bien, su capacidad para renovar nuestra percepción. La cercanía de las artes poéticas y pictóricas no se da por la habilidad técnica, sino por la capacidad que ambos medios tienen para mostrar lo nuevo y correr al compás de los nuevos tiempos, lo cual se conectaría con la otra manera de entender lo moderno, esto es, como adecuación a los tiempos "actuales". Se pregunta por la relación entre dibujo y pintura: critica a quien ve en el maestro colorista un olvidadizo del dibujo, armazón de la concepción clásica del arte. Se opone a que le pidan a la pintura grandes temas y no la dejen ser solo pintura. En el siguiente pasaje, están claramente expresadas las posibles relaciones entre las artes y el modo en que puede darse alguna aproximación, diálogo o traducción:

Las academias pusieron de moda un género de pintura que vacilaba entre la lección de historia, la enseñanza moral y la obra de arte pictórico, y venía siendo lo que en otras disciplinas se llama una transposición. Son de un arte exquisito las transposiciones de José A. Silva, en que con procedimientos que imita la manera del pintor describe literariamente lugares y escenas. Pero exigir en toda obra literaria una combinación de este género sería demasiado. Ilustra lo excesivo del caso suponer, por ejemplo, que todo poema sinfónico hubiera de sugerir tal cuadro en sus más precisos detalles. Está bien que algunos pintores traigan la emoción a sus obras: lo que se les puede pedir, sin pecar uno de exquisito, es que la sugieran hermosamente y por medios que no se salgan de los recursos con que cuenta su arte. Pero la emoción, lo mismo que la anécdota y lo mismo que la lección de historia son elemento extraño al arte de la pintura y, presentes, le dan al cuadro valor de transposición. Los que han dicho emoción han tratado de excusar con una palabra suave la invasión de un elemento literario en la obra pictórica (262).

"La pintura francesa en el pabellón de Bellas Artes" es otro de sus trabajos dedicados a la pintura. En este caso, el interés está en las diferentes formas de recepción y circulación que tiene cada arte. "La pintura viaja poco y con excesiva lentitud" (1051) dice allí, invitando al público a mirar la exposición. Las bailarinas de Degas aparecen en su texto como seres que arrancan, tanto el aplauso de los espectadores de danza, como el de los espectadores de pintura.

En "El arte francés en Bogotá", hablando de Rousseau, dice que la influencia del filósofo ginebrino se vio en todos los órdenes artísticos y en muchas actitudes hacia la vida. Equipara al clasicismo literario con el Renacimiento artístico en su búsqueda estética de la simetría y la proporción. Sin embargo, señala, es en la pintura donde hay algunos adelantados, como el Greco, quien actúa con una sensibilidad nueva, la cual los escritores empiezan a incorporar: 
No se me escapa la objeción que suscita el hecho de que el Greco pintara en plena vigencia del gusto clásico, antes de que la literatura y las artes plásticas hubieran sufrido el influjo del pensamiento nuevo y de las modernas inquietudes espirituales. La objeción se desvanece sin complicar el razonamiento. Como lo dijimos hablando de Poussin y de Claudio de Lorena en relación con el paisaje, los estados de alma suscitados por la pintura no tenían el poder contagioso de la literatura y del pensamiento de Rousseau. La pintura no tiene por objeto especial desarrollar ideas ni exponer teorías morales o filosóficas. Su influjo sobre las gentes no va más allá de las sensaciones; en tanto que las obras literarias, especialmente aquellas a las cuales dedicó su función educativa el hombre de Ginebra, tienen por objeto la difusión de sentimientos de donde los lectores adecuadamente equipados suelen deducir ideas por medio de sutiles razonamientos (198).

Como se ve, la esfera del arte de la pintura está constituida por sensaciones, no por ideas, como sí ocurre con la literatura. Si se quiere, se trata de la vieja cuestión de que la poesía es una forma de pensamiento o adivinación, mientras que la pintura es una forma de destreza o hacer. Sanín vuelve al precursor del romanticismo, y atribuye a Rousseau la renovación de la pintura y explica que el Impresionismo se deriva de él. Dice que, por falta de competencia, no se ocupa de los aspectos estéticos de las obras, sino de la función educativa de la exposición. Ello le permite reiterar que, a diferencia de libros, dramas y música, la pintura no se difunde tan rápidamente, razón por la que esta exposición, la segunda en su género en Bogotá, ${ }^{6}$ es una verdadera oportunidad para el público.

"La exposición de pintura. Los que están y los que faltan" es otro trabajo que el autor dedicó a exposiciones. Señala que la atracción del arte sólo obedece a la vocación, razón por la que expone que el interés que despierta puede ser limitado. También, indica la importancia de la renovación del pasado como propósito estético. Sin embargo, crítica a los futuristas que propugnan por la destrucción de los museos, aunque se acepta que el pasado puede ser un lastre paralizante. A uno de los artistas de los que habla en esta crítica, lo compara acudiendo a la analogía entre pintura y teatro: "De algunos dramaturgos se dice que miran el mundo desde el escenario. De Moreno Otero puede afirmarse que los aspectos del hombre y del paisaje no valen para él sino como líneas y colores" (962). De otro artista, Eugenio Peña, del cual exalta sus virtudes, señala que aprendió, no en la literatura, sino en la naturaleza, su uso de los colores. De sus tonos, dice que "sugieren la esfericidad del espacio y acarician la pupila intelectual con ondas de sentimiento inexpresable con las meras palabras" (Ibíd.).

6 Después de la de 1922, esta vino a ser la segunda exposición de arte francés en Bogotá, la cual tuvo un papel en la renovación de las corrientes en el país (Medina 184-5). 
En "Sobre una exposición y otras cosas no expuestas", Sanín Cano habla de la imagen y la producción manual como una vía de acceso privilegiado al conocimiento de civilizaciones que carecían de la escritura, con lo que afirma una especie de preeminencia de las artes plásticas. En este texto, al proponer dos paradigmas del arte, uno que va desde Giotto hasta 1880 y otro que empieza en esta fecha y va hasta el momento en que Sanín escribe (1937), señala que la diferencia estriba en la ruptura con la representación, en la emancipación de la tutela de la realidad y en la entrega a la capacidad de expresión del artista. Se da, así, la imposibilidad de que se valore la obra plástica sólo por sus méritos intrínsecos y no por su significado traducido a palabras: Por eso, "la herencia multimilenaria del hombre actual no le permite aun gozar de los méritos de una pintura o escultura si no comprende la significación o el nombre de la cosa o figura que, en su concepto, el artista ha querido representar" (333).

"La muestra española", un texto de 1938, le da ocasión para utilizar los logros de los países europeos en cada disciplina artística y señalar la preeminencia de lo plástico en España. "Poetas del color" llama a algunos de sus pintores (81). En "Homenaje al pintor don Gregorio Vásquez de Arce y Ceballos", indica que el artista, al igual que el científico, el filósofo y el escritor, surge porque el medio social tiene, en un momento histórico dado, necesidad de él. Señala que, como en Vásquez, la locura puede ser el estigma con el que los mediocres condenan a sus mejores hombres, pintores o escritores, al exilio. En "Roberto Pizano", dice del artista neogranadino: "sabía también que mientras la ciencia es engañosa y sus verdades revisadas de siglo en siglo, el arte es la más excelsa de las manifestaciones de la inteligencia humana y el único sendero por donde el hombre puede aspirar a la perfección manifestada en obras manuales" (2528).

En "Rendón" da a las obras del gran caricaturista la virtud de mostrar a los hombres tales como son, de haber disipado los preconceptos que sobre ellos se acumularon. Para hablar de que Rendón es el que ha hecho que algunos hombres se preserven del olvido, dice: “De un cómico alemán se dijo el día de su muerte que con él habían desaparecido innumerables personajes a los cuales los autores dramáticos no les habían dado sino una existencia incompleta. Rendón completó la obra de los progenitores en el caso de sus caricaturas" (5). Lo llama "humorista del lápiz" y dice: "Nació para expresarse en líneas y en frases cortas algunas de sus composiciones pertenecen al sagrado género de las parábolas" (Ibíd.).

Ahora bien, la inquietud por el parangón entre imagen y palabra y artes del tiempo y artes del espacio tiene otro escenario de realización. Esa inquietud por la diferencia de medios que proponen las palabras escritas, los sonidos, los gestos y las imágenes, que ya señalábamos, se da con insistencia en sus trabajos sobre lo escénico.

En "Vicisitudes del progreso" aparece el enfrentamiento del cine con el teatro, pero en términos económicos y de consumo: el cine vacía los teatros. Para respaldar esta reflexión de corte económico, se reafirma en su crítica a la introducción de unas artes en otras. Ve este fenómeno como el resultado del progreso científico y tecnológico y como el efecto, quizás imprevisto, de los cambios tecnológicos y del 
empobrecimiento del gusto. Es por ello que el libro puede llegar a ser un objeto de colección, con propiedades estéticas materiales, más que como un portador de texto que se valore por su contenido verbal. Ve también esta decadencia en periódicos que apelan al grabado y a la ilustración para aderezar las historias que publican. Habría allí un didactismo fácil, una especie de vulgarización por obra de la lógica periodística.

En "Los límites del arte dramático", se ocupa más directamente de la decadencia del teatro. En medio de la argumentación, propone una clasificación de las artes inspirada en las ideas del teórico alemán Hermann Barr:

Un crítico alemán, cuya actividad se ejercía sobre las obras teatrales en las revistas hebdomadarias (he olvidado su nombre), clasificaba alguna vez las artes señalando su importancia de acuerdo con la inmaterialidad o solidez del elemento explotado por cada una de ellas. Colocaba en primer término la música por ser el sonido, algo exhalado e incorpóreo, el más sutil de los elementos de que hace uso el arte de los hombres. Venía enseguida, dominando a las otras formas de expresión de belleza, la poesía lírica. Son su elemento las efímeras palabras, las frases impalpables, los tropos evanescentes. La pintura con los colores, menos inmateriales que el sonido y la palabra, venía en pos de la lírica, precediendo a la escultura y el arte arquitectónico, poseedores de materia más sólida para sus representaciones. Ocupaban el último lugar el teatro y la danza, cuyo material es tan sólido, tan poco inmaterial, que necesita reparar constantemente las pérdidas resultantes del ejercicio de sus facultades con una cuidadosa nutrición (119).

Esta exposición es intencionada, pues busca, por un lado, establecer diferencias cualitativas y, por el otro, conferir al teatro la facultad de usar al ser humano completo, con sus gestos y capacidad expresiva corporal, como materia prima y objeto. En esta ocasión, Sanín también usa el lenguaje para ensalzar la capacidad de otro elemento comunicativo, en este caso el gesto, que supera a las palabras. El actor debe ocuparse, por tal razón, de lo que va más allá de lo verbal: "El episodio dramático tiene valor principalmente como rumbo en que se desenvuelve el carácter de un hombre; pero las cualidades literarias de las frases que este hombre diga nos tienen sin cuidado a los espectadores del drama" (123). Por ello, que el arte dramático hubiera echado mano de las palabras una vez da cuenta de una de sus primeras pérdidas de pureza. De hecho, la decadencia que Sanín le atribuye al arte teatral en el momento que escribe sobre este tema, 1929, es responsabilidad del comercio ilícito que lo dramático tiene con la literatura:

Cada día es más temerario y absorbente el predominio de la palabra sobre la acción. Bastardeando de su origen y abandonando la senda que conduce a su destino manifiesto, el drama ha venido a ser un arte literario contra todo procedente y toda razón. El teatro no es literatura, y cuando llega a serlo y cuanto más lo sea, más se aparta de sus principios. En este momento de la vida triste y cataléptica del teatro, puede verse sin dificultad que ha llegado a esta íntima decadencia por haberse hecho demasiado literario (121). 
Incluso, al hablar de Shakespeare, subraya el valor no literario de su obra: Su gran mérito como autor de drama estriba en que por haber vivido por detrás de bastidores, consideraba al hombre como instrumento dramático y miraba la vida toda, sonriendo interiormente, desde el proscenio, no desde la torre de marfil de los literatos y los doctos. Casi todos los grandes dramaturgos han vivido como Shakespeare detrás de bastidores. Para ellos el teatro es un arte independiente, sin nexos con la literatura (123).

Por ello, según este hilo argumental, el cinematógrafo no puede ser tampoco arte literario. Ni tampoco puede serlo aquel teatro artístico que incorpora elementos visuales de otras artes y pone el énfasis en la música o la danza.

En "La literatura y el cine", de 1944, considera nuevamente si el cinematógrafo constituye una amenaza, pero esta vez para el ejercicio literario. Considera, primero, sus relaciones: dice que no se vinculan, que su único nexo es el teatro, pero que el teatro no pertenece a la literatura. Para explicar las diferencias, vuelve a la clasificación ya propuesta, tomada de Bahr:

Hermann Bahr clasificaba las artes según el material que utilizaban, y su valor estaba para él en razón inversa de la solidez del elemento de que hacían uso. Según este criterio el arte puro, el más excelso, llamado a producir más hondas y trascendentales impresiones, era la música, por la calidad etérea y vaga de su material, que son los sonidos; venía en seguida la poesía, cuyo elemento, la palabra, tiene también algo de incorpóreo y evanescente; le seguía la pintura, en la cual los colores y la tela tienen las cualidades de los cuerpos físicos; venía en pos la escultura por lo macizo y pesado del mármol y el bronce, y ocupaba el último lugar el arte histriónico, por ser el hombre lo más evidente y material, el elemento de que se sirve para comunicar ideas y sensaciones. De esta manera el arte literario (poesía, novela) queda muy por encima del teatro como arte representativo. Este orden de categorías, aunque un tanto voluntarioso, muestra la distancia que va de la literatura al cine. Más cerca vendría quedando la pantalla de la pintura y del arte puramente histriónico (310).

Dice que el cine no ha influido en la decadencia del arte literario. Y que este último fenómeno se debe a razones económicas y no estéticas. Señala que el cine tiene porvenir y no presente, toda vez que hay en él posibilidades que no se hallan en las demás expresiones artísticas. Por eso, su dictamen es contundente:

Pienso que el cine tiene a su disposición elementos de tanto porvenir y riqueza como no los ha poseído arte ninguno. El teatro estuvo cohibido por las unidades de lugar y tiempo. Para el cine el tiempo no existe y el lugar es su esclavo. El cine puede representar el espectáculo de un hombre que habiendo caído de una torre y convirtiéndose en una masa informe, surge, se alza en el aire, recorre a la inversa el camino de la muerte y vuelve a mostrarse en la totalidad 
de sus funciones. El cine tiene por esto un porvenir tan fastuoso en el mundo del arte como la teoría de los "cuanta" y de la relatividad en el orbe inextenso y atemporal de la física hodierna (311).

En “¿Es literatura el teatro?”, Sanín da una de sus visiones más integrales del problema de la clasificación de las artes y resume sus planteamientos de décadas anteriores, añadiendo algunos ejemplos más contundentes. Primero, discute si el teatro es literatura o si es un arte independiente, como la pintura y la música. Se inclina por esta última opción, y añade algo que había quedado apenas esbozado en su texto de 1905. La verdadera amenaza para la independencia de las artes es la contaminación con lo literario (63).

Vuelve a Bahr y a su clasificación, pero añade consideraciones sobre medios reproductibles como la fotografía y el cine, a los que el teórico de la estética citado no aplicó sus reflexiones y su taxonomía. Sin embargo, Sanín especula con el bajo lugar que, en el sistema estético del alemán, pudo haber tenido el cine: "suponemos que le daría inferior situación en la escala de valores, porque a la solidez del hombre se añaden como materia prima la máquina fotográfica y decoraciones ficticias en que lo espiritual se desvanece entre las exigencias del movimiento físico y la necesidad de aprovechar las sombras y los colores" (64).

Ahora bien, como en otros casos, las diferencias entre las artes engendran consideraciones cualitativas e, incluso, escalas de valoración atendiendo a la pureza o impureza de los medios: "Una de las deficiencias del teatro y del cine como obras de arte nacen de esta irremediable y desventurada circunstancia de estar los dos géneros de espectáculo en la necesidad de dos personas por lo menos para integrar la obra y lograr el efecto que aspira el primero y más significativo de los que intervienen en su ejecución" (65). Al ser algo de orden estrictamente individual, el arte, en la óptica de Sanín, no admite producciones donde la subjetividad está disgregada en una colectividad productora.

De esta cooperación entre diferentes profesionales, se sigue una promiscuidad de medios que hace dudar del estatuto artístico de tales producciones. Transcribimos la cita en extenso para hacer evidentes los matices de la exposición de Sanín:

El arte, como apunta la experiencia por todas partes, es obra individual. Se sabe que ha habido autores conjuntos de obras de teatro, pero ni son éstas las más notables de su época, ni hay constancia efectiva de la manera como se hacía el trabajo. En la pintura suele haber colaboración, pero es apenas una ayuda mercenaria. El poeta, el compositor de música es una voluntad individual. No ha menester auxilio para completar su obra. Los recitadores y los artistas instrumentales pueden cooperar con él a la difusión de la obra y de su fama, pero no le agregan a la obra méritos o cualidades de que careciera al salir de la mente de su creador. La película cinematográfica no es obra de un individuo y además e ingloriosamente no nace de una inspiración o impulso exclusivamente artísticos. Lo más vecino a la obra de arte en el espectáculo que ofrece la pantalla es el boceto o 
esquema de la película. Muy a menudo este boceto no es la creación original de quien lo presenta. Suele ser tomado de una novela más o menos célebre, de un drama o comedia ya famosos. En sí, esta circunstancia no es característica del cine. Dramas de soberbia estructura y magníficas vistas sentimentales fueron arreglos hechos por Shakespeare de otros dramas o sacados por él de obras conocidas como novelas, dramas ajenos o historias escritos por otros (65).

Otros elementos que impiden que sea arte son su carácter masivo, su rebajamiento al nivel de la comprensión del vulgo y su tolerancia a dejar participar en la realización final de la obra a profesionales de la técnica y no de la estética. El rechazo del cine como arte se fundamentaría de este modo en un argumento estético: la imposibilidad de encontrar en él un medio característico e irreductible. Es decir, el cinematógrafo, al contrario de las artes, no tiene un lenguaje identificable: "Creemos hallar la explicación de este revés perpetuo, de esta mala sombra continua del oficio cinematográfico en la combinación de varias artes para dar la impresión humana de movimiento" (68). Ve en la falta de sutileza, en los trucos a la vista, uno de los más grandes defectos del cine. También en este caso, la intromisión de lo literario resulta corruptora. Por ello, se refiere con desdén a los recursos narrativos a que acuden los realizadores cuando deben están en un atolladero:

Cuando los artesanos de una película suponen que el público de seis continentes no va a ser capaz de entender el significado completo de su producción crean en el espacio una voz providente que explica cuanto la película no pudo hacer inteligible; se oye en los espacios con autoridad de persona docente y así quedan salvados los vacíos del ubicuo, del igualitario proceso de la pantalla (69).

\section{Conclusión}

Si bien la preocupación de Sanín Cano por los límites entre las artes fue recurrente en su trabajo, el ensayista estuvo lejos de construir una teoría o un marco sistemático para comprender las diferencias entre las artes. Sin embargo, son notorios, por un lado, su interés en tipificar lo moderno en el arte a partir de la fidelidad que cada manifestación artística podía guardarle a su medio y, por el otro, el respeto por ese postulado en sus trabajos de más de medio siglo. Esta última circunstancia, incluso, obligaría a guardar reservas con la tesis proverbial de que fue un autor que, al elegir el ensayo como su medio de comunicación, fue siempre desordenado y contradictorio.

De igual manera, cabe resaltar la importancia que, en esta definición de límites entre las artes, tiene el parangón entre poesía y pintura, un motivo clásico que reaparece, no sólo en los textos sobre pintura en los que Sanín criticó la intromisión de lo literario en lo plástico, sino también en reflexiones sobre formas contemporáneas de la producción estética, como el cine o la tira cómica, o en otras, como la decoración, 
la arquitectura, el teatro y la fotografía. De cierta manera, es necesario que el estudio de las ideas estéticas en Colombia y América Latina, que tiene en Sanín Cano uno de sus capítulos más importantes, integre con lo ya analizado sobre sus textos acerca del impresionismo lo que puede aportar una lectura de sus trabajos sobre otros temas plásticos y visuales. Esto, además, permitiría un conocimiento más completo de las ideas del Sanín Cano crítico literario, que ha captado la atención de la academia y la historia literaria en Colombia.

\section{Referencias}

Batteux, Charles. Les beaux-arts réduits a un même principe. Paris: Durand Libraire, 1746. Medio impreso.

Benjamin, Walter. "La obra de arte en la era de la reproductibilidad técnica". Discursos interrumpidos I, Filosofía del arte y de la historia. Trad. Jesús Aguirre Madrid: Taurus, 1989. 16-57. Medio impreso.

Danto, Arthur. Después del fin del arte. El arte contemporáneo y el linde de la historia. Trad. Elena Neerman Rodríguez. Barcelona: Paidós, 1999. Medio impreso.

Fernández Uribe, Carlos Arturo y Sofía Arango. Fundamentos estéticos de la crítica literaria en Colombia. Finales del siglo XIX y comienzos del siglo XX. Medellín: Editorial Universidad de Antioquia, 2011. Medio impreso.

Focillon, Henri. "Éloge de la main". Vie des formes, suivi de Éloge de la main. Paris: Presses Universitaires de France, 1943. 101-128. Medio impreso.

Giraldo, Efrén. La poética del esbozo. Baldomero Sanín Cano, Hernando Téllez, Nicolás Gómez Dávila. Bogotá: Universidad de los Andes, 2014. Medio impreso.

Greenberg, Clement. Arte y cultura. Ensayos críticos. Trad. Justo G. Beramendi Barcelona: Paidós, 1979. Medio impreso.

Jiménez, David. Historia de la crítica literaria en Colombia 1850-1950. Bogotá: Universidad Nacional de Colombia, 2009. Medio impreso.

Lessing, Gotthold Ephraim. Laocoonte o sobre los límites entre la pintura y la poesía. Trad. Enrique Palau. Madrid: Orbis, 1986. Medio impreso.

Marchán Fiz, Simón. La estética en la cultura moderna: de la ilustración a la crisis del estructuralismo. Madrid: Alianza Editorial, 2000. Medio impreso.

Medina, Álvaro. Procesos del arte en Colombia. Bogotá: Instituto Colombiano de Cultura, 1978. Medio impreso.

Sanín Cano, Baldomero. "La pintura francesa en el pabellón de Bellas Artes". El gráfico 873 (1929): 1051-1052. Medio impreso.

---. “¿Es literatura el teatro?”. El humanismo y el progreso del hombre. Buenos Aires: Losada, 1955. 63-70. Medio impreso.

---. “De lo exótico”. Escritos. Bogotá: Instituto colombiano de cultura, 1977. 335-346.

Medio impreso. 
---. “Del origen del arte”. Ensayos. Bogotá: Ministerio de Educación de Colombia, 1942. 133-139. Medio impreso.

---. "Diálogo indiferente”. Ideología y cultura. Tomo I, vol. III. Antología y prólogo Otto Morales Benítez. Bogotá: Universidad externado de Colombia, 1998. 108-110. Medio impreso.

---. "El arte de Berta Singermann". Ideología y cultura. Tomo I, vol. II. Antología y prólogo Otto Morales Benítez. Bogotá: Universidad externado de Colombia, 1998. 79-83. Medio impreso.

---. "El arte francés en Bogotá". Crítica y arte. Bogotá: Universidad Externado de Colombia, Fondo Editorial Universidad Eafit, 2012. 193-201. Medio impreso.

---. "El arte y la línea recta”. La civilización manual y otros ensayos. Medellín: Tomás Carrasquilla, 1975. 72-76. Medio impreso.

---. "El impresionismo en Bogotá". Revista Contemporánea 1904-1905 (2006): 129134 y 259-262. Bogotá: Universidad Externado de Colombia. Medio impreso. ---. "El vitáfono”. Ideología y cultura. Tomo I, vol. I. Antología y prólogo Otto Morales Benítez. Bogotá: Universidad Externado de Colombia, 1998. 169-171. Medio impreso.

--- "Homenaje al pintor don Gregorio Vásquez Arce y Ceballos". Ideología y cultura. Tomo I, vol. III. Antología y prólogo Otto Morales Benítez. Bogotá: Universidad externado de Colombia, 1998. 17-23. Medio impreso.

---. "La civilización manual". La civilización manual y otros ensayos. Medellín: Tomás Carrasquilla, 1975. 36-45. Medio impreso.

---. “La exposición de pintura los que están y los que faltan”. El Gráfico 894 (1936): 959-962. Medio impreso.

---. "La literatura y el cine". Ideología y cultura. Tomo I, vol. IV. Antología y prólogo Otto Morales Benítez. Bogotá: Universidad externado de Colombia, 1998. 309-331. Medio impreso.

---. "La muestra española”. Ideología y cultura. Tomo I, vol. III. Antología y prólogo Otto Morales Benítez. Bogotá: Universidad externado de Colombia, 1998. 80-82. Medio impreso.

--- “La tiranía del medio ambiente”. Revista Contemporánea 1904-1905 (2006): 292299. Bogotá: Universidad Externado de Colombia. Medio impreso.

---. "Los límites del arte dramático". La civilización manual y otros ensayos. Baldomero Sanín Cano. Medellín: ediciones Tomás Carrasquilla, 1975. 118-124. Medio impreso.

---. “Rendón”. El Heraldo de Antioquia 1475, 5 (7 de diciembre de 1931). Medio impreso.

---. "Roberto Pizano”. El gráfico 873 (1929): 2527-2528. Medio impreso.

---. “Shakespeare amenazado”. La civilización manual y otros ensayos. Medellín: Tomás Carrasquilla, 1975. 152-157. Medio impreso. 
--.. "Sobre una exposición y otras cosas no expuestas". Ideología y cultura. Tomo I, vol. II. Antología y prólogo Otto Morales Benítez. Bogotá: Universidad externado de Colombia, 1998. 330-339. Medio impreso.

---. "Tenaz como la fealdad". Pesadumbre de la belleza y otros cuentos y apólogos. Bogotá: Seix Barral, 1997. 72-79. Medio impreso.

---. "Un arte educativo". Ideología y cultura. Tomo I, vol. III. Antología y prólogo Otto Morales Benítez. Bogotá: Universidad externado de Colombia, 1998. 240-242. Medio impreso.

---. "Un enigma sentimental resuelto (John Ruskin)”. Escritos. Bogotá: Instituto colombiano de cultura, 1977. 503-512. Medio impreso.

---. "Una gran aventura el arte". Crítica y arte. Bogotá: Universidad Externado de Colombia - Fondo Editorial Universidad Eafit, 2012. 173-192. Medio impreso. ---. "Ver y no imitar". Ideología y cultura. Tomo I, vol. IV. Antología y prólogo Otto Morales Benítez. Bogotá: Universidad externado de Colombia, 1998. 407-408. Medio impreso.

---. "Vicisitudes del progreso". Ideología y cultura. Tomo I, vol. I. Antología y prólogo Otto Morales Benítez. Bogotá: Universidad externado de Colombia, 1998. 163-166. Medio impreso.

Solana, Guillermo (comp.). El Impresionismo: la visión original: antología de la crítica de arte (1867-1895). Madrid: Siruela, 1997. Medio impreso.

Tatarkiewicz, Władysław. "Classification of arts in antiquity". Journal of the History of Ideas 2 (abril-junio 1963): 231-240. Medio impreso.

---. Historia de seis ideas. Arte, belleza, forma, creatividad, mímesis, experiencia estética. Trad. Francisco Rodríguez Martín. Madrid: Tecnos, 2010. Medio impreso. Tobón, Daniel Jerónimo. “Arte y cultura: el pensamiento estético de Baldomero Sanín Cano". Poligramas 31 (junio 2009): 141-161. Medio impreso.

Recibido: 05 mayo 2014 Aceptado: 16 septiembre 2015 